\title{
A HIGHER-ORDER FACET QUADRILATERAL COMPOSITE SHELL ELEMENT
}

\author{
TARUN KANT $^{1 *}$ AND RAKESH K. KHARE $^{2}$ \\ ${ }^{1}$ Department of Civil Engineering, Indian Institute of Technology Bombay, Powai, Mumbai 400 076, India \\ ${ }^{2}$ Department of Civil Engineering, Shri G. S. Institute of Technology and Science, Indore 452 003, India
}

\begin{abstract}
A $C^{0}$ finite element formulation of flat faceted element based on a higher-order displacement model is presented for the analysis of general, thin-to-thick, fibre reinforced composite laminated plates and shells. This theory incorporates a realistic non-linear variation of displacements through the shell thickness, and eliminates the use of shear correction coefficients. The discrete element chosen is a nine-noded quadrilateral with five and nine degrees of freedom per node.

A comparison of results is also made with the 2-D thin classical and 3-D exact analytical results, and finite element solutions with 9-noded first-order element. (C) 1997 John Wiley \& Sons, Ltd.
\end{abstract}

Int. J. Numer. Meth. Engng., 40, 4477-4499 (1997)

No. of Figures: 7. No. of Tables: 8. No. of References: 33.

KEY WORDS: shell element; higher-order theory; facet composite shell element; flat shell element; finite element method; shear deformable flat shell element

\section{INTRODUCTION}

Flat facet shell elements are popular and are integral parts of any general purpose finite element code (e.g., ABAQUS, ${ }^{1}$ ANSYS,${ }^{2}$ MSC/NASTRAN,${ }^{3}$ NISA II, ${ }^{4}$ SAP IV,${ }^{5}$ SAP80, ${ }^{6}$ etc.). With the advent of high-speed computers it is also possible now a days to employ large number of elements, to approximate even a curved shell by flat facet elements. An account of various types of elements used in the analysis of shells, their merits and demerits, is given in a paper by Meek and Tan. ${ }^{7}$ They have also presented a good review of triangular faceted shell elements developed till 1985 and have themselves presented a flat shell triangular element using linear strain triangle for membrane representation and a plate bending behaviour with loof nodes. Their element is free from the deficiencies of displacement incompatibility, singularity with coplanar elements, inability to model intersections and low-order membrane strain representation usually associated with the, then faceted shell elements. Allman ${ }^{8}$ presented a triangular facet finite element with cubic polynomial displacement fields using six degrees of freedom at the element vertices for the analysis of general thin shells. Madenci and Barut ${ }^{9}$ and Onate et al. ${ }^{10}$ have also presented triangular elements free from locking phenomenon.

* Correspondence to T. Kant, Civil Engineering Department, Indian Institute of Technology, Powai, Mumbai 400076 , Bombay, India

Contract grant sponsor: Aeronautics Research and Development Board, Ministry of Defence, Government of India; Contract grant number: Aero/RD-134/100/10/94-95/801 
A simple four-noded quadrilateral shell element (called QUAD4) based on isoparametric principles with reduced order of integration for shear terms was first presented by MacNeal. ${ }^{11}$ Belytschko et al. ${ }^{12}$ used a nine-noded Lagrangian degenerated element with $2 \times 2$ integration to free the stress projection from parasitic shear and membrane stresses. The authors have used a simple model to show the similarity of the causes of shear and membrane locking and their relationship to parasitic shear and membrane stresses and described how mode-decomposition stress projection methods can be used to alleviate shear and membrane locking. They have also described a challenging set of test problems for linear analysis of shells. MacNeal and Harder ${ }^{13}$ have also proposed a standard set of test problems to include all of the parameters which have important effects on element accuracy.

$\mathrm{MacNeal}^{14}$ compared eight- and nine-noded elements and improved the performance of eightnoded elements, to match that of nine-noded elements. Cook $^{15}$ presented a 24 degrees of freedom quadrilateral shell element obtained by the very simple process of combining standard membrane and bending formulations with devices for inclusion of membrane-bending coupling and warping effects.

The elements discussed above either used Kirchhoff's ${ }^{16}$ or Reissner ${ }^{17}$-Mindlin's ${ }^{18}$ theory in their formulation. The present paper is an attempt towards the use of a higher-order shear deformation theory in the formulation of a nine-noded $C^{0}$ Lagrangian isoparametric element with 9 degrees of freedom per node for the analysis of thin-to-thick fibre reinforced composite and sandwich laminated plates and shells. A parallel formulation is also done with 5 degrees of freedom per node using Reissner-Mindlin's first-order shear deformation theory and results obtained by these theories are compared with available 2-D plate/shell solutions as well as 3-D exact analytical solutions. A drilling degree of freedom concept is utilized following Cook $^{15}$ in the formulation to include an additional rotation degree of freedom about the transverse normal, thus having 6 and 10 degrees of freedom per node in the global directions for the first-order and the higher-order shear deformation theories, respectively.

\section{THEORY AND FORMULATION}

The first step in the element formulation is to place the element in a local co-ordinate system with $x y z$ that is oriented with reference to the element geometry and is defined by using the global $X Y Z$ co-ordinates of element nodes (Figure 1). The local co-ordinates are set using the same procedure as given in Zienkiewicz and Taylor. ${ }^{19}$ The local $x$-axis is oriented towards the first side of the element considering first node as the origin. The side intersecting at this origin is considered for the computation of normal vector ( $z$-axis) of the element. The $y$-axis is then established using $x$ - and $z$-axes. Element properties are formulated in the local co-ordinate system and transformed to global directions before assembly.

A flat faceted element of a composite laminate consisting of laminas with isotropic/orthotropic material properties oriented arbitrarily in space (Figure 1) is considered and is shown in Figure 2. In the present theory, the displacement components of a generic point in the element, by grouping the terms corresponding to membrane behaviour and flexure behaviour, are assumed in the form:

$$
\begin{aligned}
& \text { membrane | flexure } \\
& u(x, y, z)=u_{0}(x, y)+z^{2} u_{0}(x, y) \mid+z \theta_{y}(x, y)+z^{3} \theta_{y}^{*}(x, y) \\
& v(x, y, z)=v_{0}(x, y)+z^{2} v_{0}(x, y) \mid-z \theta_{x}(x, y)-z^{3} \theta_{x}^{*}(x, y) \\
& w(x, y, z)=\quad \mid w_{0}(x, y)
\end{aligned}
$$



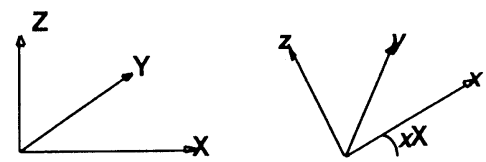

Global and local co-ordinate systems

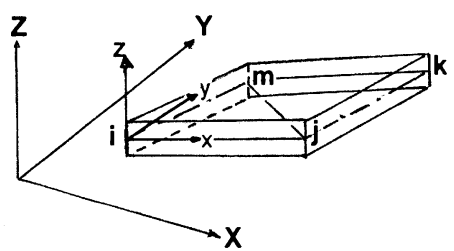

Figure 1. Geometry and co-ordinate systems

Typical Lamina

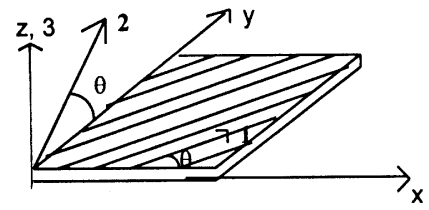

$(1,2,3)$ - Lamina reference axes.

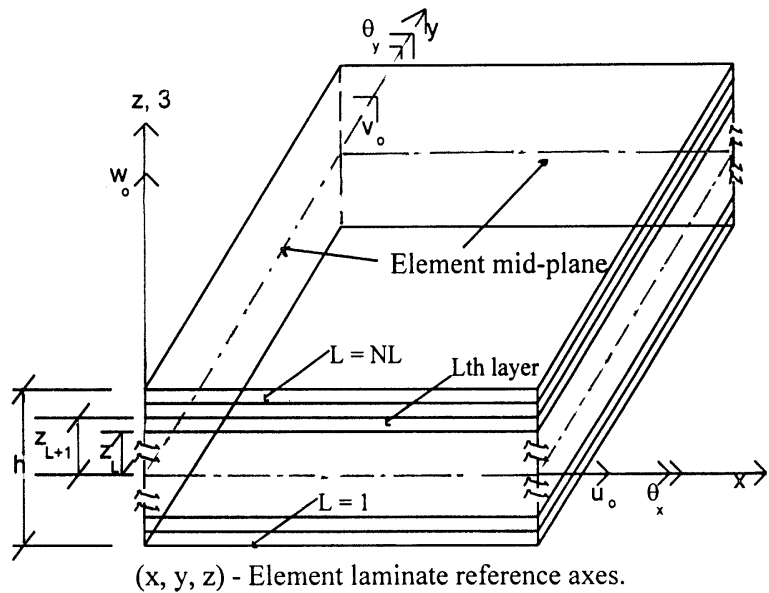

Figure 2. Element laminate geometry with positive set of lamina/laminate reference axes, displacement components and fibre orientation

where the terms $u, v$ and $w$ are the displacements of a general point $(x, y, z)$ in an element of the laminate in the $x, y$ and $z$ directions, respectively. The parameters $u_{0}, v_{0}, w_{0}, \theta_{x}$ and $\theta_{y}$ are the displacements and rotations of the middle plane while $u_{0}^{*}, v_{0}^{*}, \theta_{x}^{*}$ and $\theta_{y}^{*}$ are the higher-order 
displacement parameters defined at the mid-surface. By substituting these relations into the general linear strain-displacement relations, following relations are obtained.

$$
\begin{aligned}
\varepsilon_{x} & =\varepsilon_{x_{0}}+z \chi_{x}+z^{2} \varepsilon_{x_{0}}^{*}+z^{3} \chi_{x}^{*} \\
\varepsilon_{y} & =\varepsilon_{y_{0}}+z \chi_{y}+z^{2} \varepsilon_{y_{0}}^{*}+z^{3} \chi_{y}^{*} \\
\gamma_{x y} & =\varepsilon_{x y_{0}}+z \chi_{x y}+z^{2} \varepsilon_{x y_{0}}^{*}+z^{3} \chi_{x y}^{*} \\
\gamma_{x z} & =\phi_{x}+z \chi_{x z}+z^{2} \phi_{x}^{*} \\
\gamma_{y z} & =\phi_{y}+z \chi_{y z}+z^{2} \phi_{y}^{*}
\end{aligned}
$$

where

$$
\begin{aligned}
\left(\varepsilon_{x_{0}}, \varepsilon_{y_{0}}, \varepsilon_{x y_{0}}\right) & =\left(\frac{\partial u_{0}}{\partial x}, \frac{\partial v_{0}}{\partial y}, \frac{\partial u_{0}}{\partial y}+\frac{\partial v_{0}}{\partial x}\right) \\
\left(\chi_{x}, \chi_{y}, \chi_{x y}\right) & =\left(\frac{\partial \theta_{y}}{\partial x},-\frac{\partial \theta_{x}}{\partial y}, \frac{\partial \theta_{y}}{\partial y}-\frac{\partial \theta_{x}}{\partial x}\right) \\
\left(\varepsilon_{x_{0}}^{*}, \varepsilon_{y_{0}}^{*}, \varepsilon_{x y_{0}}^{*}\right) & =\left(\frac{\partial u_{0}^{*}}{\partial x}, \frac{\partial v_{0}^{*}}{\partial y}, \frac{\partial u_{0}^{*}}{\partial y}+\frac{\partial v_{0}^{*}}{\partial x}\right) \\
\left(\chi_{x}^{*}, \chi_{y}^{*}, \chi_{x y}^{*}\right) & =\left(\frac{\partial \theta_{y}^{*}}{\partial x},-\frac{\partial \theta_{x}^{*}}{\partial y}, \frac{\partial \theta_{y}^{*}}{\partial y},-\frac{\partial \theta_{x}^{*}}{\partial x}\right) \\
\left(\phi_{x}, \phi_{y}, \chi_{x z}, \chi_{y z}\right) & =\left(\theta_{y}+\frac{\partial w_{0}}{\partial x},-\theta_{x}+\frac{\partial w_{0}}{\partial y}, 2 u_{0}^{*}, 2 v_{0}^{*}\right) \\
\left(\phi_{x}^{*}, \phi_{y}^{*}\right) & =\left(3 \theta_{y}^{*},-3 \theta_{x}^{*}\right)
\end{aligned}
$$

The constitutive relations for a typical lamina $L$ with reference to the fibre-matrix co-ordinate axes $(1,2,3)$ can be written as

$$
\left\{\begin{array}{c}
\sigma_{1} \\
\sigma_{2} \\
\tau_{12} \\
\tau_{13} \\
\tau_{23}
\end{array}\right\}^{L}=\left[\begin{array}{ccccc}
C_{11} & C_{12} & 0 & 0 & 0 \\
C_{12} & C_{22} & 0 & 0 & 0 \\
0 & 0 & C_{33} & 0 & 0 \\
0 & 0 & 0 & C_{44} & 0 \\
0 & 0 & 0 & 0 & C_{55}
\end{array}\right]^{L} \quad\left\{\begin{array}{c}
\varepsilon_{1} \\
\varepsilon_{2} \\
\gamma_{12} \\
\gamma_{13} \\
\gamma_{23}
\end{array}\right\}^{L}
$$

where $\left(\sigma_{1}, \sigma_{2}, \tau_{12}, \tau_{13}, \tau_{23}\right)$ are the stresses, and the linear strain components are given by $\left(\varepsilon_{1}, \varepsilon_{2}\right.$, $\left.\gamma_{12}, \gamma_{13}, \gamma_{23}\right)$. These are with reference to lamina co-ordinates in the element, $C_{i j}$ 's are the elastic constants of the $L$ th lamina and are related to engineering constants by the following relations:

$$
\begin{aligned}
& C_{11}=\frac{E_{1}}{1-v_{12} v_{21}}, \quad C_{12}=\frac{v_{12} E_{2}}{1-v_{12} v_{21}}, \quad C_{22}=\frac{E_{2}}{1-v_{12} v_{21}} \\
& C_{33}=G_{12}, \quad C_{44}=G_{13}, \quad C_{55}=G_{23}, \quad \frac{v_{12}}{E_{1}}=\frac{v_{21}}{E_{2}}
\end{aligned}
$$


The stress-strain relations for the Lth lamina in the element co-ordinates $(x, y, z)$ can be written as

$$
\boldsymbol{\sigma}=\mathbf{Q} \varepsilon
$$

where

and

$$
\boldsymbol{\sigma}=\left(\sigma_{x}, \sigma_{y}, \tau_{x y}, \tau_{x z}, \tau_{y z}\right)^{\mathrm{t}}
$$

$$
\boldsymbol{\varepsilon}=\left(\varepsilon_{x}, \varepsilon_{y}, \gamma_{x y}, \gamma_{x z}, \sigma_{y z}\right)^{\mathrm{t}}
$$

are the stress and strain vectors with respect to the element co-ordinates, and, following the usual transformation rule of stress/strains between the lamina $(1,2,3)$ and the element $(x, y, z)$ co-ordinate systems, the elements of the $\mathbf{Q}$ matrix are obtained as

$$
\mathbf{Q}=\mathbf{T}^{\mathrm{t}} \mathbf{C} \mathbf{T}
$$

for the Lth lamina in the element and the T matrix is defined in Appendix I.

The total potential energy $\Pi$ of the system with a middle surface area $A$ enclosing a space of volume ' $v$ ' and loaded with an equivalent load vector $\mathbf{q}$ corresponding to the nine degrees of freedom of a point on the middle surface can be written as

$$
\begin{aligned}
\Pi & =\frac{1}{2} \int_{v} \boldsymbol{\varepsilon}^{\mathrm{t}} \boldsymbol{\sigma} \mathrm{d} v-\int_{v} \mathbf{u}^{\mathrm{t}} \mathbf{p} \mathrm{d} v \\
& =\frac{1}{2} \int_{A}\left(\boldsymbol{\varepsilon}^{\mathrm{t}} \boldsymbol{\sigma} \mathrm{d} z\right) \mathrm{d} A-\int_{A} \mathbf{d}^{\mathrm{t}} \mathbf{q} \mathrm{d} A
\end{aligned}
$$

in which

$$
\begin{aligned}
& \mathbf{u}=(u, v, w)^{\mathrm{t}}, \quad \mathbf{p}=\left(p_{x}, p_{y}, p_{z}\right)^{\mathrm{t}} \\
& \mathbf{d}=\left(u_{0}, v_{0}, w_{0}, \theta_{x}, \theta_{y}, u_{0}^{*}, v_{0}^{*}, \theta_{x}^{*}, \theta_{y}^{*}\right)^{\mathrm{t}}
\end{aligned}
$$

By substituting the expression for the strain components given by equation (2) in the above expression for potential energy, the function given by equation (4a) is then minimized while carrying out explicit integration through the shell thickness. This leads to the following stress resultants:

$$
\begin{aligned}
& {\left[\begin{array}{llll}
N_{x} & N_{x}^{*} & M_{x} & M_{x}^{*} \\
N_{y} & N_{y}^{*} & M_{y} & M_{y}^{*} \\
N_{x y} & N_{x y}^{*} & M_{x y} & M_{x y}^{*}
\end{array}\right]=\sum_{L=1}^{\mathrm{NL}} \int_{z_{L}}^{z_{L+1}}\left\{\begin{array}{c}
\sigma_{x} \\
\sigma_{y} \\
\tau_{x y}
\end{array}\right\}\left(1, z^{2}, z, z^{3}\right) \mathrm{d} z } \\
& {\left[\begin{array}{lll}
Q_{x} & Q_{x}^{*} & S_{x} \\
Q_{y} & Q_{y}^{*} & S_{y}
\end{array}\right]=\sum_{L=1}^{\mathrm{NL}} \int_{z_{L}}^{z_{L+1}}\left\{\begin{array}{l}
\tau_{x z} \\
\tau_{y z}
\end{array}\right\}\left(1, z^{2}, z\right) \mathrm{d} z }
\end{aligned}
$$


where NL is the number of layers. Upon integration these expressions are rewritten in matrix form as

$$
\left\{\begin{array}{l}
\mathbf{N} \\
\mathbf{M} \\
\mathbf{Q}
\end{array}\right\}=\left[\begin{array}{ccc}
\mathbf{D}_{m} & \mathbf{D}_{c} & \mathbf{0} \\
\mathbf{D}_{c}^{\mathrm{t}} & \mathbf{D}_{b} & \mathbf{0} \\
\mathbf{0} & \mathbf{0} & \mathbf{D}_{s}
\end{array}\right]\left\{\begin{array}{l}
\boldsymbol{\varepsilon}_{0} \\
\boldsymbol{\chi} \\
\boldsymbol{\phi}
\end{array}\right\}
$$

or

$$
\overline{\boldsymbol{\sigma}}=\mathbf{D} \bar{\varepsilon}
$$

in which

$$
\begin{array}{ll}
\mathbf{N}=\left(N_{x}, N_{y}, N_{x y}, N_{x}^{*}, N_{y}^{*}, N_{x y}^{*}\right)^{\mathrm{t}}, & \varepsilon_{0}=\left(\varepsilon_{x 0}, \varepsilon_{y 0}, \varepsilon_{x y 0}, \varepsilon_{x 0}^{*}, \varepsilon_{y 0}^{*}, \varepsilon_{x y 0}^{*}\right)^{\mathrm{t}} \\
\mathbf{M}=\left(M_{x}, M_{y}, M_{x y}, M_{x}^{*}, M_{y}^{*}, M_{x y}^{*}\right)^{\mathrm{t}}, & \chi=\left(\chi_{x}, \chi_{y}, \chi_{x y}, \chi_{x}^{*}, \chi_{y}^{*}, \chi_{x y}^{*}\right)^{\mathrm{t}} \\
\mathbf{Q}=\left(Q_{x}, Q_{y}, Q_{x}^{*}, Q_{y}^{*}, S_{x}, S_{y}\right)^{\mathrm{t}} & \boldsymbol{\phi}=\left(\phi_{x}, \phi_{y}, \phi_{x}^{*}, \phi_{y}^{*}, \chi_{x z}, \chi_{y z}\right)^{\mathrm{t}}
\end{array}
$$

The individual sub-matrices of the rigidity matrix $\mathbf{D}$ are defined in Appendix II.

\section{FINITE ELEMENT FORMULATION}

For the present study, a nine-noded quadrilateral (Lagrangian family) two-dimensional $C^{0}$ continuous isoparametric element with nine degrees of freedom per node is developed. The displacement vector $\mathbf{d}$ at any point on the mid-surface is given by

$$
\mathbf{d}=\sum_{i=1}^{\mathrm{NN}} N_{i}(x, y) \mathbf{d}_{i}
$$

where $\mathbf{d}_{i}$ is the displacement vector corresponding to node $i, N_{i}$ is the interpolating or shape function associated with node $i$, and $\mathrm{NN}$ is the total number of nodes per element (nine in this case).

Knowing the generalized displacement vector $\mathbf{d}$ at all points within the element, the generalized mid-surface strains at any point given by equations (2b) can be expressed in terms of nodal displacements in matrix form as follows:

$$
\overline{\boldsymbol{\varepsilon}}=\sum_{i=1}^{\mathrm{NN}} \mathbf{B}_{i} \mathbf{d}_{i}
$$

where $\mathbf{B}_{i}$ is a differential operator matrix of shape functions. ${ }^{20}$

Using the standard finite element technique, the total domain is discretized into NE subdomains or elements such that

$$
\Pi(\mathbf{d})=\sum_{e=1}^{\mathrm{NE}} \Pi^{e}(\mathbf{d})
$$


where $\Pi$ and $\Pi^{\mathrm{e}}$ are the potential energies of the structure and the element respectively. We further have

$$
\Pi^{e}(\mathbf{d})=U^{e}-W^{e}
$$

in which $U^{e}$ and $W^{e}$ are the internal strain energy and external work done respectively for the element and by evaluating the $\mathbf{D}$ and $\mathbf{B}_{i}$ matrices as given by equations (6b) and (8), respectively, the element stiffness matrix can be obtained by using the standard relation,

$$
\mathbf{K}_{i j}^{\mathbf{e}}=\int_{-1}^{1} \int_{-1}^{1} \mathbf{B}_{i}^{\mathbf{t}} \mathbf{D} \mathbf{B}_{j}|\mathbf{J}| \mathrm{d} \xi \mathrm{d} \eta
$$

Similarly, the distributed pressure loading on an element is easily transformed into equivalent nodal loads using the virtual work principle. Thus the consistent load vector $\mathbf{P}_{i}$ due to a uniformly distributed transverse load $\mathbf{q}$ can be written as

$$
\mathbf{P}_{i}=\int_{-1}^{1} \int_{-1}^{1} \mathbf{N}_{i}^{\mathrm{t}} \mathbf{q}|\mathbf{J}| \mathrm{d} \xi \mathrm{d} \eta, \quad i=1, \ldots, N
$$

where $|\mathbf{J}|$ is the determinant of the standard Jacobian matrix.

Before assembly, the element load vector and stiffness matrix are transformed to global co-ordinate system $(X Y Z)$ by the simple transformation rules as described in Zienkiewicz and Taylor. ${ }^{19}$ The forces and displacements of a node are transformed from the global to the local system by a matrix $\mathbf{L}_{\mathrm{g}}$ giving

$$
\begin{aligned}
\mathbf{d}_{i} & =\mathbf{L}_{\mathrm{g}} \mathbf{d}_{i}^{\mathrm{g}} \\
\mathbf{P}_{i} & =\mathbf{L}_{\mathrm{g}} \mathbf{P}_{i}^{\mathrm{g}}
\end{aligned}
$$

in which matrix $\mathbf{L}_{\mathrm{g}}$ is defined in Appendix III and $\mathbf{d}_{i}^{\mathrm{g}}$ and $P_{i}^{\mathrm{g}}$ are the displacement and load vectors in the global co-ordinate system corresponding to node $i$ defined as

$$
\begin{aligned}
\mathbf{d}_{i}^{\mathrm{g}} & =\left(u_{0}^{\mathrm{g}}, v_{0}^{\mathrm{g}}, w_{0}^{\mathrm{g}}, \theta_{x}^{\mathrm{g}}, \theta_{y}^{\mathrm{g}}, u_{0}^{* \mathrm{~g}}, v_{0}^{* \mathrm{~g}}, \theta_{x}^{* \mathrm{~g}}, \theta_{y}^{* \mathrm{~g}}, \theta_{z}^{\mathrm{g}}\right) \\
\mathbf{P}_{i}^{\mathrm{g}} & =\left(P_{x 0}^{\mathrm{g}}, P_{y 0}^{\mathrm{g}}, P_{z 0}^{\mathrm{g}}, M_{x}^{\mathrm{g}}, M_{y}^{\mathrm{g}}, P_{x 0}^{* \mathrm{~g}}, P_{y 0}^{* \mathrm{~g}}, M_{x}^{* \mathrm{~g}}, M_{y}^{* \mathrm{~g}}, M_{z}^{\mathrm{g}}\right)
\end{aligned}
$$

superscript ' $\mathrm{g}$ ' indicates the components in global co-ordinate system. In the global co-ordinate system the rotation about the global $z$-direction and moment about the global $z$-direction are introduced, thus introducing the tenth degree of freedom at each node. For the whole set of displacements and forces acting on nodes of an element, equations (13) can therefore be expressed as

$$
\mathbf{d}_{\mathrm{e}}=\mathbf{T}_{\mathrm{g}} \mathbf{d}_{\mathrm{e}}^{\mathrm{g}} \quad \text { and } \quad \mathbf{P}^{\mathrm{e}}=\mathbf{T}_{\mathrm{g}} \mathbf{P}^{\mathrm{ge}}
$$

By the rules of orthogonal transformation the stiffness matrix of an element in the global co-ordinate becomes

$$
\mathbf{K}^{\mathrm{ge}}=\mathbf{T}_{\mathrm{g}}^{\mathrm{t}} \mathbf{K}^{\mathrm{e}} \mathbf{T}_{\mathrm{g}}
$$


In both the above equations $T_{\mathrm{g}}$ is given by

$$
\mathbf{T}_{g}=\left[\begin{array}{cccc}
\mathbf{L}_{\mathrm{g}} & \mathbf{0} & \mathbf{0} & \cdots \\
\mathbf{0} & \mathbf{L}_{\mathrm{g}} & \mathbf{0} & \\
\mathbf{0} & \mathbf{0} & \mathbf{L}_{\mathrm{g}} & \\
\vdots & & &
\end{array}\right]
$$

a diagonal matrix built of $\mathbf{L}_{\mathrm{g}}$ matrices in a number equal to that of the nodes in the element. Knowing the element stiffness and the load matrix in the common global co-ordinate system, they are assembled to represent a particular geometry with prescribed boundary conditions, also in the global co-ordinate system. The governing equations are then solved to obtain discrete set of displacements, referred to the global system. These displacements are transformed to local system for determining the stress resultants in the local system using equations (2) and (6) at the desired locations.

\section{NUMERICAL RESULTS}

A computer program based on the theoretical formulation described earlier is developed for the analysis of composite laminated plates and shells. To validate the accuracy of element an obstacle course for shell elements described in Belytschko et al. ${ }^{12}$ is undertaken. Similarly to validate the accuracy of formulation the examples of shells having 3-D exact solution are considered. All the computations are made in PC-AT/486 DX2@66 MHz machine in DOS environment and programme is compiled with FORTRAN-77 compiler. A parallel computer code is also developed based on the Reissner-Mindlin's first-order theory.

The problems, under the so-called obstacle course for the shell elements, described by Belytschko et al. ${ }^{12}$ are shown in Figure 3. The problem parameters for obstacle course are given in Table I. These problems are considered as the critical test cases and are dealt with by many authors to test their elements. The test problems are here analysed using exact (E), selective (S) and uniform reduced (R) Gauss integration rules in the evaluation of energy terms comprising of bending, membrane and shear contributions. The order of integration used for each element is shown in the bracket for bending, membrane and shear contributions respectively with $\mathrm{E}, \mathrm{S}$ and $\mathrm{R}$ notations in respective tables.

Example 1 (Scordelis - Lo roof). This typical shell roof problem is analysed analytically by Scordelis and $\mathrm{Lo}^{21}$ and Scordelis. ${ }^{22}$ The same roof problem is taken as part of obstacle course for shell elements described by Belytschko et al. ${ }^{12}$ The length of the roof is $50 \cdot 0$ units, radius is $25 \cdot 0$ units and the thickness is of 0.25 units. The Young's modulus of the material is $4.32 \times 10^{8}$ units and Poisson's ratio is taken as zero. The roof is supported on rigid diaphragms at each end and is loaded by a uniform vertical gravity load of $90 \cdot 0$ units per unit area.

The results obtained for this problem are shown in Figure 4 as the convergence study in the results of the higher-order shear deformation theory (HOST) and the first-order shear deformation theory (FOST) and the values of ratio between computed deflection $\left(w_{\text {FEM }}\right)$ to accepted theoretical deflection ( $\left.w_{\text {analytical }}\right)$ are presented in Table II. The results obtained by both first-order and higher-order shear theories are converging even with four exactly integrated elements on the curved side. 


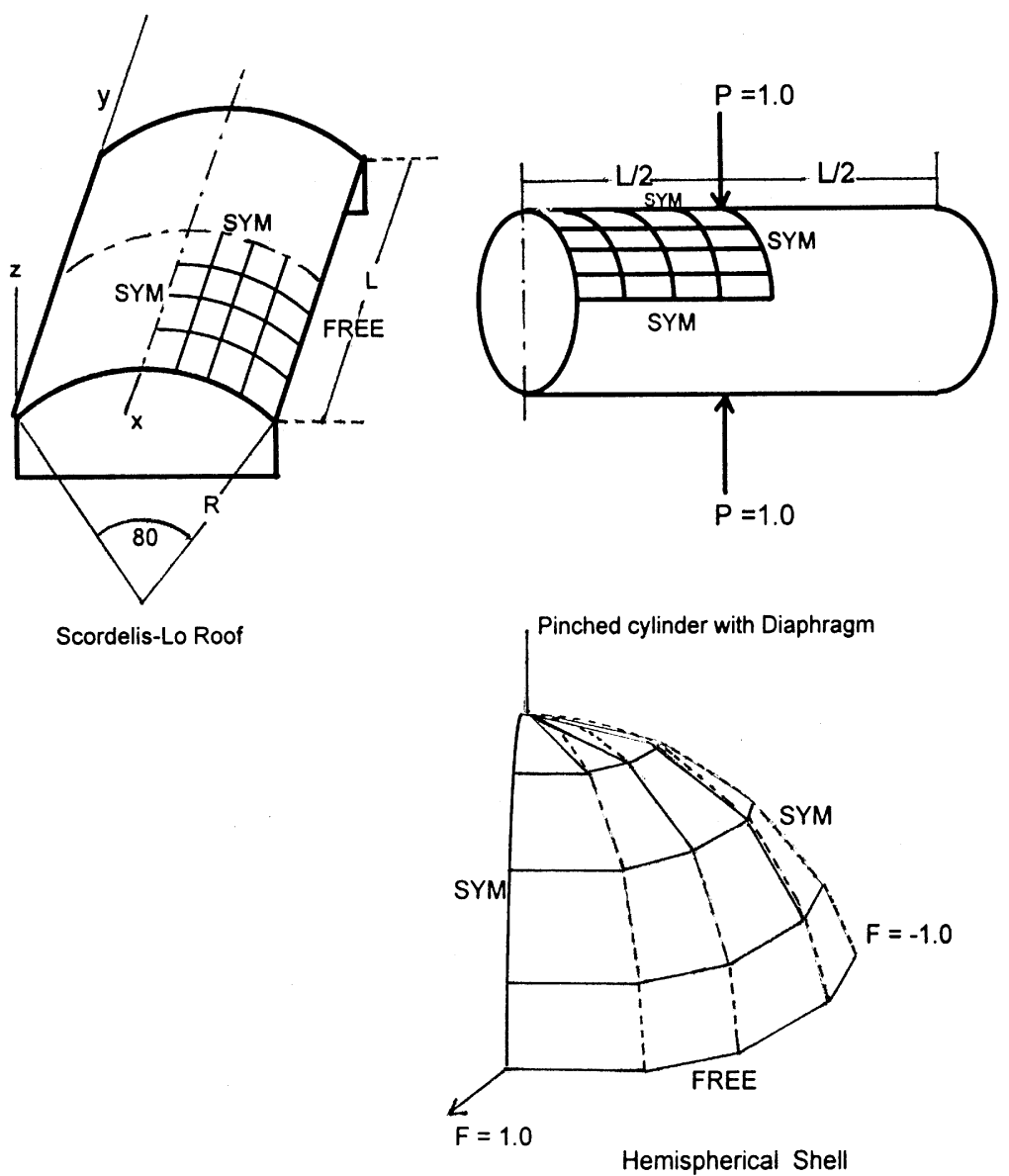

Figure 3. Obstacle course for shell element

Example 2 (Pinched cylinder with diaphragms). A pinched cylinder with end diaphragms is solved by Belytschko et al. ${ }^{12}$ The length of the roof is $600 \cdot 0$ units, radius is $300 \cdot 0$ units and is of 3.0 units thick. The Young's modulus of the material is $3 \cdot 0 \times 10^{6}$ units and the Poisson's ratio is $0 \cdot 3$. The cylinder is constrained at each end by a rigid diaphragm as shown in Figure 3. The cylinder is subjected to two radially opposing point loads of unit magnitude as shown in Figure 3.

The results obtained for this problem are presented in Table III and Figure 5, which are converging to the analytical solutions with reduced integration in 8 elements on curved side. The effect of shear and membrane locking discussed by Belytschko et al. $^{12}$ is predominant in this problem as good convergence is obtained with selective and uniform reduced Gauss integration.

Example 3 (Hemispherical shell). A hemispherical shell as shown in Figure 3 is solved by Belytschko et al. $^{12}$ (originally by Morley and Morris ${ }^{23}$ ). The radius of the shell is $10 \cdot 0$ units and is of 0.04 units thick. The Young's modulus of material is $6 \cdot 825 \times 10^{7}$ units and Poisson's ratio is $0 \cdot 3$. 
Table I. Problem parameters for obstacle course ${ }^{12}$

\begin{tabular}{|c|c|c|c|}
\hline & $\begin{array}{l}\text { Example } 1 \\
\text { (Scordelis-Lo } \\
\text { roof) }\end{array}$ & $\begin{array}{c}\text { Example } 2 \\
\text { (Pinched cylinder } \\
\text { with diaphragms) }\end{array}$ & $\begin{array}{c}\text { Example } 3 \\
\text { (Hemispherical } \\
\text { shell) }\end{array}$ \\
\hline $\begin{array}{l}\text { Length } \\
(L)\end{array}$ & $50 \cdot 0$ & $600 \cdot 0$ & - \\
\hline Radius & $25 \cdot 0$ & $300 \cdot 0$ & $10 \cdot 0$ \\
\hline $\begin{array}{l}\text { Thickness } \\
(h)\end{array}$ & $0 \cdot 25$ & $3 \cdot 0$ & $0 \cdot 04$ \\
\hline $\begin{array}{l}\text { Young's modulus } \\
(E)\end{array}$ & $4.32 \times 10^{8}$ & $3.0 \times 10^{6}$ & $6.825 \times 10^{7}$ \\
\hline $\begin{array}{l}\text { Poisson's ratio } \\
(v)\end{array}$ & $0 \cdot 0$ & $0 \cdot 3$ & $0 \cdot 3$ \\
\hline $\begin{array}{l}\text { Boundary } \\
\text { conditions }\end{array}$ & $\begin{array}{l}\text { Supported at each } \\
\text { end by grid } \\
\text { diaphragm }\end{array}$ & $\begin{array}{l}\text { Constrained at } \\
\text { each end by a grid } \\
\text { diaphragms }\end{array}$ & $\begin{array}{c}\text { Bottom } \\
\text { circumferential } \\
\text { edge of hemisphere } \\
\text { is free }\end{array}$ \\
\hline Loading & $\begin{array}{l}\text { Uniform vertical } \\
\text { gravity load of } \\
90.0 \text { per unit area }\end{array}$ & $\begin{array}{c}\text { Opposing radial } \\
\text { loads as shown in } \\
\text { Figure } 3\end{array}$ & $\begin{array}{c}\text { Opposing radial } \\
\text { point loads } \\
\text { alternating at } 90^{\circ} \\
\text { as shown in Figure } \\
3, F= \pm 2 \cdot 0\end{array}$ \\
\hline $\begin{array}{l}\text { Thin shell } \\
\text { analytical } \\
\text { solution }\end{array}$ & $\begin{array}{c}\text { Vertical } \\
\text { displacement at } \\
\text { midside of free } \\
\text { edge }=0.3024\end{array}$ & $\begin{array}{c}\text { Radial } \\
\text { displacement at } \\
\text { point load: } \\
0 \cdot 18248 \times 10^{-4}\end{array}$ & $\begin{array}{c}\text { Radial } \\
\text { displacement at } \\
\text { loaded points: } \\
0.0924\end{array}$ \\
\hline
\end{tabular}

This problem is idealised in different manner by different authors. In the present paper the authors have idealised the problem following Cook $^{15}$ by taking a small hole of radius 0.01 units at top of sphere. In the analysis advantage of symmetry is taken and only quarter part of the hemispherical shell is analysed. The bottom circumferential edge of the hemisphere is free and it is subjected to two radial point loads of magnitude 2.0 units alternating at $90^{\circ}$ as shown in the Figure 3. Smaller size of elements are taken at the top than bottom part of the shell.

The results obtained for this problem are presented in Table IV. It can easily be observed that the effect of membrane locking is maximum in this problem, and results are not converging to the accepted theoretical result with exact integration even with $8 \times 8$ mesh but they are converging with uniform reduced integration. It is observed here too, as is said by Belytschko et al., ${ }^{12}$ the uniform reduced integration gives good results in this case. These problems are analysed using global boundary conditions only to study the behaviour of elements in general. But the computer program also has the provision of skewed or local boundary conditions.

Example 4. The analysis of three groups of a long layered laminated circular cylindrical shell, namely, $0^{\circ}, 90 / 0^{\circ}$ and $0^{\circ} / 90 / 0^{\circ}$ is carried out and the results are compared with the available elasticity solutions given by Ren. ${ }^{26}$ The shell roof has a radius $R=10 \cdot 0$ units, a length $L=30 \cdot 0$ 


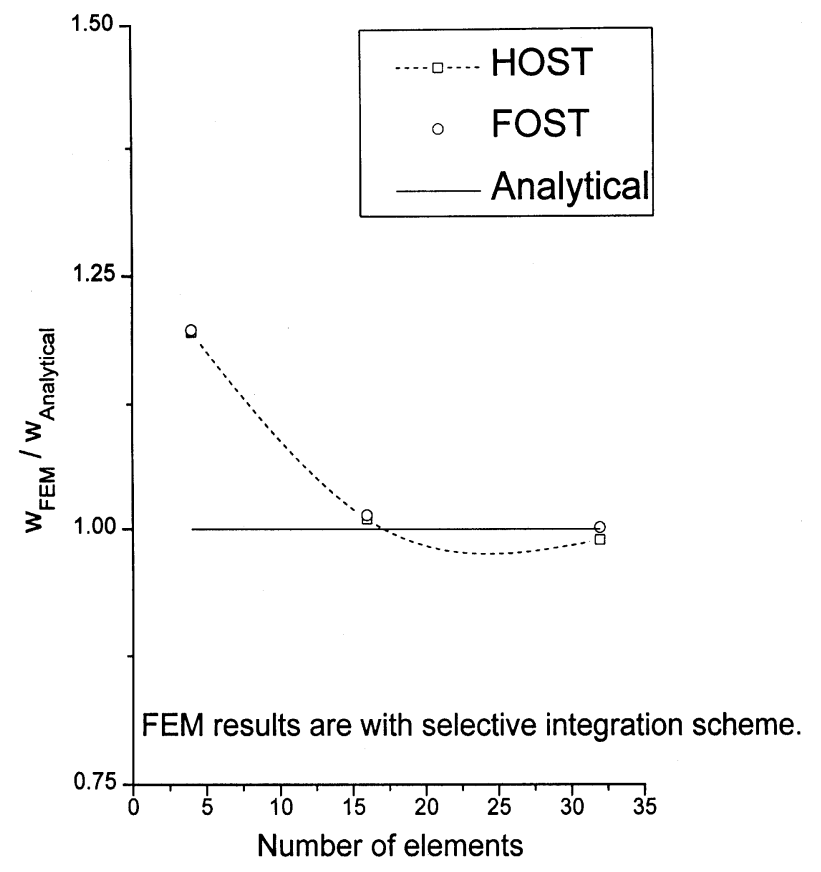

Figure 4. Convergence study in finite element results of Scordelis-Lo cylindrical roof $(R / h=100)$

Table II. Scordelis-Lo roof results reported as the ratio of computed deflection to accepted theoretical deflection $^{12}(R / h=100)$

\begin{tabular}{lcccccccc}
\hline & \multicolumn{8}{c}{ Mesh size } \\
\cline { 2 - 9 } & \multicolumn{7}{c}{$1 \times 1$} & \multicolumn{2}{c}{$2 \times 2$} & & $4 \times 4$ & & $8 \times 4$ \\
\cline { 2 - 9 } $\begin{array}{l}\text { Scheme of } \\
\text { integration }\end{array}$ & HOST & FOST & HOST & FOST & HOST & FOST & HOST & FOST \\
\hline E $(3 \times 3 \times 3)$ & 2.3230 & 2.3230 & 1.137 & 1.1400 & 0.9898 & 1.0040 & 0.9810 & 0.9705 \\
S $(3 \times 3 \times 2)$ & 3.4590 & 3.4560 & 1.198 & 1.1960 & 1.0140 & 1.0100 & 1.0020 & 0.9895 \\
R $(2 \times 2 \times 2)$ & 3.4920 & 3.4980 & 1.198 & 1.1960 & 1.0123 & 1.0180 & 1.0025 & 1.0050 \\
\hline
\end{tabular}

units and subtended angle $\phi=\pi / 3$. The lamina material properties considered in the analysis are as follows:

$$
E_{1}=25 \times 10^{6}, \quad E_{2}=10^{6}, \quad G_{12}=G_{13}=0.5 \times 10^{6}, \quad G_{23}=0.2 \times 10^{6}, \quad v_{12}=v_{23}=v_{13}=0 \cdot 25
$$

All the shells are simply supported on both the edges in the radial direction, and subjected to a transverse normal load of $q=q_{0} \sin (\pi x / a)$, in which $q_{0}=1$, ' $x$ ' and ' $a$ ' are shown in Figure 6 . Radius $R=10$, angle $\phi=\pi / 3$. The values of maximum transverse deflection and normal stress, 
Table III. Pinched cylinder results reported as the ratio of computed deflection to accepted theoretical deflection $^{12}(R / h=100)$

\begin{tabular}{|c|c|c|c|c|c|c|c|c|}
\hline \multirow[b]{3}{*}{$\begin{array}{l}\text { Scheme of } \\
\text { integration }\end{array}$} & \multicolumn{8}{|c|}{ Mesh size } \\
\hline & \multicolumn{2}{|c|}{$2 \times 2$} & \multicolumn{2}{|c|}{$4 \times 4$} & \multicolumn{2}{|c|}{$8 \times 4$} & \multicolumn{2}{|c|}{$16 \times 4$} \\
\hline & HOST & FOST & HOST & FOST & HOST & FOST & HOST & FOST \\
\hline $\mathrm{E}(3 \times 3 \times 3)$ & 0.0456 & 0.0474 & $0 \cdot 3739$ & $0 \cdot 3767$ & 0.678 & 0.6820 & 0.807 & $0 \cdot 8114$ \\
\hline $\mathrm{S}(3 \times 3 \times 2)$ & $0 \cdot 1085$ & $0 \cdot 1086$ & $0 \cdot 6694$ & 0.6694 & 0.9654 & 0.9530 & $1 \cdot 0044$ & $1 \cdot 0050$ \\
\hline $\mathrm{R}(2 \times 2 \times 2)$ & $0 \cdot 1352$ & $0 \cdot 1359$ & $0 \cdot 6927$ & 0.6937 & 0.9717 & 0.9723 & 1.0171 & $1 \cdot 0180$ \\
\hline
\end{tabular}

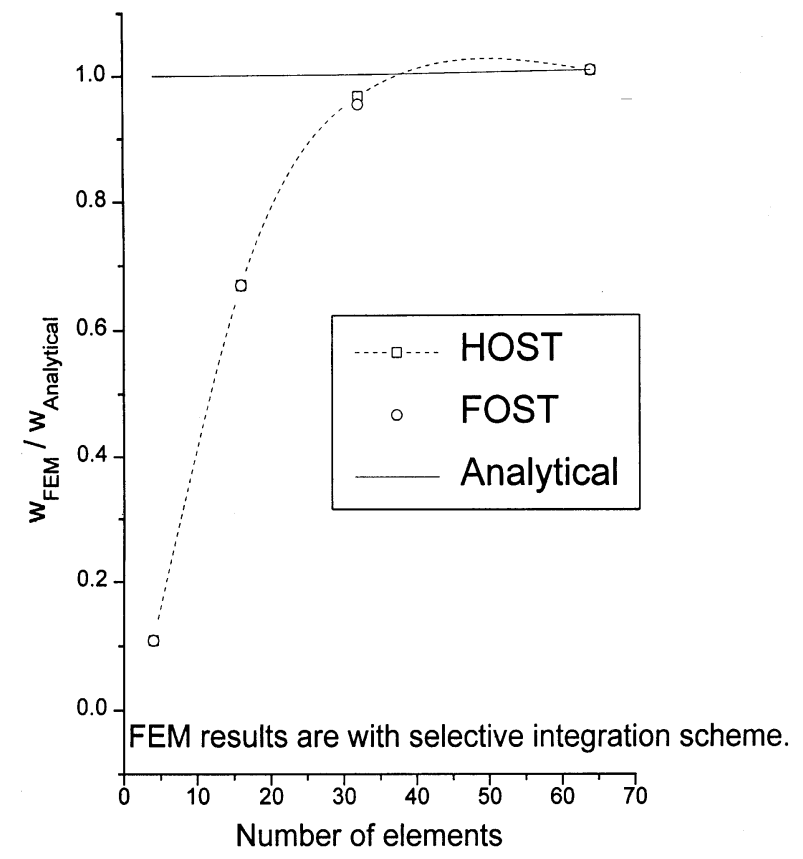

Figure 5. Convergence study in finite element results of Pinched cylinder $(R / h=100)$

normalized by

$$
\bar{w}=\frac{10 E_{2} w}{q_{0} h S^{4}}, \quad \bar{\sigma}_{x}=\frac{\sigma_{x}}{q_{0} S^{2}}, \quad S=R / h
$$

are presented in Table $\mathrm{V}$ for different $R / h$ ratios, namely 2, 4, 10, 50 and 100 . The values of stresses computed by the present finite element formulation are of the nearest Gauss quadrature points to the locations of values of stresses indicated in the Table V. The results have good agreement with 
Table IV. Hemispherical shell results reported as the ratio of computed deflection to accepted theoretical deflection $^{12}(R / h=250)$

\begin{tabular}{lccccccccc}
\hline & \multicolumn{8}{c}{ Mesh size } \\
\cline { 2 - 9 } & \multicolumn{2}{c}{$1 \times 1$} & \multicolumn{2}{c}{$2 \times 2$} & \multicolumn{2}{c}{$4 \times 4$} & & $8 \times 8$ \\
\cline { 2 - 9 } $\begin{array}{l}\text { Scheme of } \\
\text { integration }\end{array}$ & HOST & FOST & HOST & FOST & HOST & FOST & HOST & FOST \\
\hline E $(3 \times 3 \times 3)$ & $2.6 \times 10^{-3}$ & $3.0 \times 10^{-3}$ & 0.0292 & 0.0310 & 0.1115 & 0.1127 & 0.6120 & 0.5393 \\
S $(3 \times 3 \times 2)$ & 1.0230 & 1.0841 & 1.0450 & 1.0663 & 0.6200 & 0.6210 & 0.5344 & 0.8040 \\
R $(2 \times 2 \times 2)$ & 19.500 & 31.831 & $5 \cdot 8410$ & 4.7050 & 1.0450 & 1.0860 & 0.8396 & 1.1590 \\
\hline
\end{tabular}

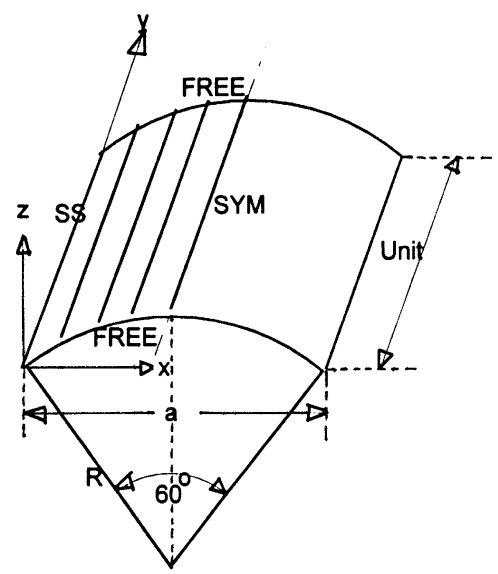

Figure 6. Long laminated cylindrical shell with FEM idealization

the exact solutions, except in very thick cases, i.e. for $R / h$ ratio as 2 . It is observed from these results that the displacement field presented by first-order shear deformation theory are close to the elasticity solution in case of unidirectional and bidirectional cylindrical shell but in case of 3-ply cylindrical shell the displacement given by higher-order shear deformation theory are close to the elasticity solution. The stresses computed by the higher-order shear deformation theory (HOST) are close to the elasticity solution in comparison to the stresses computed by the first-order shear deformation theory (FOST) in all the cases. All the computations made in the present finite element formulation are with exact integration scheme thereby giving some error in results at $R / h$ equal to 100 in case of bidirectional shell. The results improve when selective integration scheme is applied by reducing the integration points by one in the computation of shear energy terms. In general from thin shell to thick shell with $R / h$ ratio 4 , the results of the higher-order formulation are better.

As the formulation of elasticity solution given by $\operatorname{Ren}^{26}$ is done for cylindrical shells supported in the radial direction and the global $z$-direction is different in the present finite element formulation, the concept of skewed boundary condition ${ }^{27}$ has been considered in the present analysis. 
Table V. Maximum normalized deflection and normal stress in long cylindrical shells

\begin{tabular}{|c|c|c|c|c|c|c|}
\hline \multirow{2}{*}{$\begin{array}{l}\text { Quantity } \\
R / h\end{array}$} & \multicolumn{3}{|c|}{$\bar{w}(x=a / 2, z=0)$} & \multicolumn{3}{|c|}{$\bar{\sigma}_{x}(x=a / 2, z=0)$} \\
\hline & HOST & FOST & $\operatorname{Ren}^{26}$ & HOST & FOST & $\operatorname{Ren}^{26}$ \\
\hline \multicolumn{7}{|c|}{ unidirectional cylindrical shell $\left(0^{\circ}\right)$} \\
\hline 2 & $0 \cdot 8462$ & $0 \cdot 9067$ & $0 \cdot 9986$ & $\begin{array}{r}-1.4750 \\
1.5563\end{array}$ & $\begin{array}{r}-0.8035 \\
0.6813\end{array}$ & $\begin{array}{r}-2.455 \\
1.907\end{array}$ \\
\hline 4 & $0 \cdot 2763$ & $0 \cdot 2820$ & $0 \cdot 3120$ & $\begin{array}{r}-1.0394 \\
1.0275\end{array}$ & $\begin{array}{r}-0.7731 \\
0.7113\end{array}$ & $\begin{array}{r}-1.331 \\
1.079\end{array}$ \\
\hline 10 & $0 \cdot 1069$ & $0 \cdot 1070$ & $0 \cdot 1150$ & $\begin{array}{r}-0.8078 \\
0.7844\end{array}$ & $\begin{array}{r}-0.7555 \\
0.7285\end{array}$ & $\begin{array}{r}-0.890 \\
0.807\end{array}$ \\
\hline 50 & $0 \cdot 0748$ & $0 \cdot 0749$ & $0 \cdot 0770$ & $\begin{array}{r}-0.7468 \\
0.7330\end{array}$ & $\begin{array}{r}-0.7422 \\
0.7330\end{array}$ & $\begin{array}{r}-0.767 \\
0.752\end{array}$ \\
\hline 100 & $0 \cdot 0736$ & $0 \cdot 0736$ & $0 \cdot 0755$ & $\begin{array}{r}-0.7429 \\
0.7214\end{array}$ & $\begin{array}{r}-0.7442 \\
0.7229\end{array}$ & $\begin{array}{r}-0.758 \\
0.751\end{array}$ \\
\hline $100^{*}$ & $0 \cdot 0744$ & $0 \cdot 0741$ & $0 \cdot 0755$ & $\begin{array}{r}-0 \cdot 7474 \\
0 \cdot 7440\end{array}$ & $\begin{array}{r}-0.7453 \\
0.7420\end{array}$ & $\begin{array}{r}-0.758 \\
0.751\end{array}$ \\
\hline \multicolumn{7}{|c|}{ bidirectional cylindrical shell $\left(90 / 0^{\circ}\right)$} \\
\hline 2 & $1 \cdot 5734$ & $1 \cdot 6775$ & $2 \cdot 079$ & $\begin{array}{r}-0.4018 \\
2.5375\end{array}$ & $\begin{array}{r}-0 \cdot 2613 \\
2 \cdot 2540\end{array}$ & $\begin{array}{r}-0 \cdot 644 \\
3 \cdot 348\end{array}$ \\
\hline 4 & $0 \cdot 7174$ & $0 \cdot 7356$ & $0 \cdot 854$ & $\begin{array}{r}-0 \cdot 2913 \\
2 \cdot 2600\end{array}$ & $\begin{array}{r}-0 \cdot 2459 \\
2 \cdot 1900\end{array}$ & $\begin{array}{r}-0.384 \\
2 \cdot 511\end{array}$ \\
\hline 10 & $0 \cdot 4552$ & $0 \cdot 4575$ & $0 \cdot 493$ & $\begin{array}{r}-0 \cdot 2436 \\
2 \cdot 1610\end{array}$ & $\begin{array}{r}-0.2366 \\
2 \cdot 1530\end{array}$ & $\begin{array}{r}-0 \cdot 277 \\
2 \cdot 245\end{array}$ \\
\hline 50 & $0 \cdot 3946$ & $0 \cdot 3951$ & $0 \cdot 409$ & $\begin{array}{r}-0 \cdot 2288 \\
2 \cdot 1060\end{array}$ & $\begin{array}{r}-0 \cdot 2296 \\
2 \cdot 1100\end{array}$ & $\begin{array}{r}-0 \cdot 240 \\
2 \cdot 165\end{array}$ \\
\hline 100 & $0 \cdot 3549$ & $0 \cdot 3999$ & $0 \cdot 403$ & $\begin{array}{r}-0.2058 \\
1.8930\end{array}$ & $\begin{array}{r}-0 \cdot 2313 \\
2 \cdot 1250\end{array}$ & $\begin{array}{r}-0 \cdot 237 \\
2 \cdot 158\end{array}$ \\
\hline $100^{*}$ & $0 \cdot 3961$ & $0 \cdot 3916$ & $0 \cdot 403$ & $\begin{array}{r}-0 \cdot 2330 \\
2 \cdot 1510\end{array}$ & $\begin{array}{r}-0.2290 \\
2 \cdot 1090\end{array}$ & $\begin{array}{r}-0 \cdot 237 \\
2 \cdot 158\end{array}$ \\
\hline \multicolumn{7}{|c|}{ 3-ply cylindrical shell $\left(0 / 90 / 0^{\circ}\right)$} \\
\hline 2 & $1 \cdot 1678$ & $1 \cdot 1179$ & 1.4360 & $\begin{array}{r}-2 \cdot 090 \\
2 \cdot 240\end{array}$ & $\begin{array}{r}-0.859 \\
0.680\end{array}$ & $\begin{array}{r}-3 \cdot 467 \\
2 \cdot 463\end{array}$ \\
\hline 4 & $0 \cdot 3790$ & $0 \cdot 3367$ & $0 \cdot 4570$ & $\begin{array}{r}-1 \cdot 325 \\
1 \cdot 301\end{array}$ & $\begin{array}{r}-0.814 \\
0.724\end{array}$ & $\begin{array}{r}-1 \cdot 772 \\
1.367\end{array}$ \\
\hline 10 & $0 \cdot 1273$ & $0 \cdot 1180$ & $0 \cdot 1440$ & $\begin{array}{r}-0.889 \\
0.854\end{array}$ & $\begin{array}{r}-0.788 \\
0.751\end{array}$ & $\begin{array}{r}-0.995 \\
0.897\end{array}$ \\
\hline 50 & 0.0782 & 0.0779 & $0 \cdot 0808$ & $\begin{array}{r}-0.776 \\
0.761\end{array}$ & $\begin{array}{r}-0.774 \\
0.760\end{array}$ & $\begin{array}{r}-0.798 \\
0.782\end{array}$ \\
\hline 100 & 0.0766 & 0.0767 & 0.0787 & $\begin{array}{r}-0.771 \\
0.754\end{array}$ & $\begin{array}{r}-0.773 \\
0.757\end{array}$ & $\begin{array}{r}-0 \cdot 786 \\
0 \cdot 781\end{array}$ \\
\hline $100 *$ & $0 \cdot 0767$ & 0.0821 & 0.0787 & $\begin{array}{r}-0.7720 \\
0.7673\end{array}$ & $\begin{array}{r}-0.8218 \\
0.8157\end{array}$ & $\begin{array}{r}-0 \cdot 786 \\
0 \cdot 781\end{array}$ \\
\hline
\end{tabular}

* Results presented for this ratio are computed using selective integration scheme 
Example 5. An analysis of a layered laminated 3-ply $0^{\circ} / 90^{\circ} / 0^{\circ}$, and bidirectional $90 / 0^{\circ}$ circular cylindrical shell roof with all edges simply supported having same material properties as used in Example 4, is carried out and the results are compared with available elasticity solution given by $\operatorname{Ren}^{28}$ under sinusoidal loading. The shell roof has a radius $R=5 \mathrm{in}$, length $b=30$ in and subtended angle of $60^{\circ}$. A sinusoidal load $q=q_{0} \sin (\pi x / a) \sin (\pi y / b)$ is applied on the shell surface, in which ' $a$ ' and ' $b$ ' are shown in Figure 7. The thickness of each layer 3-ply shell is $h / 4$, $h / 2$ and $h / 4$ and bidirectional shell is $h / 2$ and $h / 2$. Numerical results are obtained for different $R / h$ ratios, namely 100, 10, 5 and 2 and are presented in Table VI. The maximum deflection and the normal stresses at the centre $(a / 2, b / 2)$ and the shear stress at the support $(0,0)$ are normalized as follows:

$$
\bar{w}=\frac{10 E_{2} w}{q_{0} h S^{4}}, \quad\left(\bar{\sigma}_{x}, \bar{\sigma}_{y}, \bar{\tau}_{x y}\right)=\frac{1}{q_{0} S^{2}}\left(\sigma_{x}, \sigma_{y}, \tau_{x y}\right), \quad S=R / h
$$

Again the values of the stresses computed by the present formulation are of the nearest Gauss points. The exact integration scheme is applied in all the computations. It is observed from these results that for lower $R / h$ ratios, both stress and displacement fields, given by the higher-order shear deformation theories are close to the exact three-dimensional solutions while comparing with the results of first-order shear theory.

Example 6. The example presented by Bhimaraddi ${ }^{29}$ is analysed here to compare the response of higher-order theories. Simply supported symmetric cross-ply $\left(0^{\circ} / 90^{\circ} / 0^{\circ}\right)$ spherical shell subjected to sinusoidal load ( $q \sin \pi x / a \sin \pi y / b$ ) with following properties is analysed:

$\frac{E_{1}}{E_{2}}=25 ; \frac{E_{3}}{E_{2}}=1 ; \frac{G_{13}}{E_{2}}=\frac{G_{12}}{E_{2}}=\frac{1}{2} ; \frac{G_{23}}{E_{2}}=\frac{1}{5} ; v_{12}=0 \cdot 25 ; v_{31}=0 \cdot 03 ; v_{23}=0 \cdot 4 ;$ hence $v_{13}=0 \cdot 75$

The values of normalized centre deflection $\left(w E_{2} / q\right)$ at middle surface of the shell, $x=a / 2$, $y=b / 2, z=0$, where ' $a$ ' and ' $b$ ' are curved lengths considering $x$ and $y$ as curvilinear co-ordinates, for symmetric cross-ply $\left(0 / 90 / 0^{\circ}\right)$ spherical shells (equal thickness in each layer) with

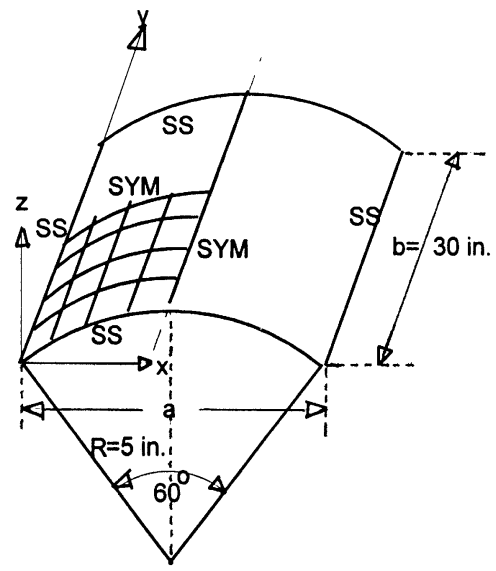

Figure 7. Simply supported laminated cylindrical shell with FEM idealization 
Table VI. Maximum normalized deflection and stresses in simply supported cylindrical shells

\begin{tabular}{|c|c|c|c|c|c|c|}
\hline \multirow[b]{2}{*}{$R / h$} & \multicolumn{3}{|c|}{ 3-ply shell $\left(0^{\circ} / 90^{\circ} / 0^{\circ}\right)$} & \multicolumn{3}{|c|}{ bidirectional shell $\left(90^{\circ} / 0^{\circ}\right)$} \\
\hline & HOST & FOST & $\operatorname{Ren}^{28}$ & HOST & FOST & $\operatorname{Ren}^{28}$ \\
\hline & \multicolumn{6}{|c|}{$\bar{w}(x=a / 2, y=b / 2, z=0)$} \\
\hline 2 & $1 \cdot 3146$ & $1 \cdot 2016$ & $1 \cdot 6728$ & 1.5595 & 1.6639 & 1.6062 \\
\hline 5 & $0 \cdot 3196$ & $0 \cdot 2719$ & 0.3694 & 0.5998 & $0 \cdot 6110$ & 0.5774 \\
\hline 10 & $0 \cdot 1429$ & $0 \cdot 1295$ & $0 \cdot 1577$ & $0 \cdot 4396$ & $0 \cdot 4422$ & $0 \cdot 4250$ \\
\hline \multirow[t]{2}{*}{100} & $0 \cdot 0531$ & $0 \cdot 0531$ & $0 \cdot 0553$ & $0 \cdot 1083$ & $0 \cdot 1083$ & $0 \cdot 1089$ \\
\hline & \multicolumn{6}{|c|}{$\bar{\sigma}_{x}$ (nearest Gauss point of $x=a / 2, y=b / 2, z= \pm h / 2$ ) } \\
\hline 2 & $\begin{array}{r}2 \cdot 482 \\
-2 \cdot 278\end{array}$ & $\begin{array}{r}0.665 \\
-0.879\end{array}$ & $\begin{array}{r}2.637 \\
-3.951\end{array}$ & $2 \cdot 515$ & $2 \cdot 230$ & $3 \cdot 914$ \\
\hline \multirow[t]{2}{*}{5} & $1 \cdot 219$ & $0 \cdot 790$ & $1 \cdot 252$ & $2 \cdot 194$ & $2 \cdot 150$ & $2 \cdot 519$ \\
\hline & -1.272 & $-0 \cdot 881$ & -1.562 & & & \\
\hline \multirow[t]{2}{*}{10} & 0.921 & $0 \cdot 810$ & 0.957 & $2 \cdot 093$ & $2 \cdot 081$ & $2 \cdot 217$ \\
\hline & -0.962 & -0.854 & -1.058 & & & \\
\hline \multirow{3}{*}{100} & 0.533 & 0.533 & 0.553 & 0.589 & $0 \cdot 590$ & 0.592 \\
\hline & -0.527 & $-0 \cdot 527$ & -0.548 & & & \\
\hline & \multicolumn{6}{|c|}{$\bar{\sigma}_{y}$ (nearest Gauss point of $x=a / 2, y=b / 2, z= \pm h / 2$ ) } \\
\hline \multirow[t]{2}{*}{2} & $0 \cdot 0473$ & $0 \cdot 0262$ & $0 \cdot 1135$ & $0 \cdot 277$ & $0 \cdot 284$ & $0 \cdot 516$ \\
\hline & -0.0346 & -0.0198 & -0.0489 & & & \\
\hline \multirow[t]{2}{*}{5} & 0.0193 & $0 \cdot 0139$ & 0.0306 & $0 \cdot 203$ & $0 \cdot 204$ & $0 \cdot 284$ \\
\hline & $-0 \cdot 0141$ & $-0 \cdot 0100$ & $-0 \cdot 0170$ & & & \\
\hline \multirow[t]{2}{*}{10} & $0 \cdot 0136$ & $0 \cdot 0121$ & $0 \cdot 0170$ & $0 \cdot 249$ & $0 \cdot 249$ & 0.305 \\
\hline & -0.0090 & -0.0080 & -0.0099 & & & \\
\hline \multirow[t]{3}{*}{100} & $0 \cdot 0152$ & $0 \cdot 0151$ & $0 \cdot 0157$ & $0 \cdot 481$ & $0 \cdot 481$ & $0 \cdot 495$ \\
\hline & $0 \cdot 0031$ & 0.0031 & 0.0032 & & & \\
\hline & \multicolumn{6}{|c|}{$\bar{\tau}_{x y}$ (nearest Gauss point of $x=a / 2, y=b / 2, z= \pm h / 2$ ) } \\
\hline 2 & -0.0364 & -0.0114 & -0.0350 & -0.0471 & -0.0344 & -0.036 \\
\hline & $0 \cdot 0473$ & $0 \cdot 0265$ & $0 \cdot 0750$ & 0.0352 & $0 \cdot 0231$ & 0.075 \\
\hline \multirow[t]{2}{*}{5} & -0.0092 & -0.0051 & -0.0096 & -0.0244 & -0.0231 & -0.020 \\
\hline & $0 \cdot 0189$ & $0 \cdot 0139$ & 0.0256 & 0.0345 & $0 \cdot 0300$ & $0 \cdot 049$ \\
\hline \multirow[t]{2}{*}{10} & -0.0038 & -0.0031 & -0.0031 & $0 \cdot 0181$ & -0.0178 & $-0 \cdot 010$ \\
\hline & $0 \cdot 0130$ & $0 \cdot 0115$ & $0 \cdot 0153$ & $0 \cdot 0403$ & 0.0389 & $0 \cdot 048$ \\
\hline \multirow[t]{2}{*}{100} & $0 \cdot 0137$ & $0 \cdot 0137$ & $0 \cdot 0174$ & 0.0272 & 0.0272 & 0.035 \\
\hline & $0 \cdot 0215$ & $0 \cdot 0214$ & 0.0253 & $0 \cdot 0430$ & $0 \cdot 0430$ & $0 \cdot 050$ \\
\hline
\end{tabular}

different $h / a$ and $R / a$ ratios are presented in Table VII. In thin regime at $h / a=0 \cdot 1$ the results presented by all the theories are approximately same except with $R / a$ ratio as 1 in which the present formulation overestimates the results in comparison to 3-D elasticity solution. With thickness ratios higher than 0.01 the results given by the present formulation are close to the 
Table VII. Maximum normalized deflection in simply supported cross-ply spherical shell $\left(0 / 90 / 0^{\circ}\right)$ with $a / b=1, R_{1}=R_{2}=R$ and equal thickness plies

\begin{tabular}{|c|c|c|c|c|c|c|}
\hline$R / a$ & $h / a$ & HOST & FOST & 3-D Exact & $\begin{array}{c}\text { Bhimaraddi² } \\
\text { PSD }\end{array}$ & CST \\
\hline 1 & $\begin{array}{l}0 \cdot 01 \\
0 \cdot 1 \\
0 \cdot 15\end{array}$ & $\begin{array}{l}75.640 \\
3.9800 \\
2.0795\end{array}$ & $\begin{array}{l}75.66 \\
3.8415 \\
1.9667\end{array}$ & $\begin{array}{c}54 \cdot 252 \\
4 \cdot 0811 \\
2 \cdot 4345\end{array}$ & $\begin{array}{c}53 \cdot 491 \\
3 \cdot 0770 \\
2 \cdot 4008\end{array}$ & $\begin{array}{r}53.486 \\
1.6564 \\
0.9438\end{array}$ \\
\hline 2 & $\begin{array}{l}0 \cdot 01 \\
0 \cdot 1 \\
0 \cdot 15\end{array}$ & $\begin{array}{l}228 \cdot 45 \\
5 \cdot 7718 \\
2 \cdot 7007\end{array}$ & $\begin{array}{r}228 \cdot 41 \\
5 \cdot 4695 \\
2 \cdot 5011\end{array}$ & $\begin{array}{r}208 \cdot 36 \\
6 \cdot 3134 \\
3 \cdot 0931\end{array}$ & $\begin{array}{r}206 \cdot 34 \\
5 \cdot 3616 \\
2 \cdot 5253\end{array}$ & $\begin{array}{l}206 \cdot 27 \\
3 \cdot 5965 \\
1 \cdot 1739\end{array}$ \\
\hline 3 & $\begin{array}{l}0 \cdot 01 \\
0 \cdot 1 \\
0 \cdot 15\end{array}$ & $\begin{array}{r}457 \cdot 14 \\
6 \cdot 4404 \\
2 \cdot 8960\end{array}$ & $\begin{array}{l}457 \cdot 75 \\
6 \cdot 0669 \\
2 \cdot 6630\end{array}$ & $\begin{array}{r}441 \cdot 81 \\
6 \cdot 9888 \\
3 \cdot 2228\end{array}$ & $\begin{array}{l}438 \cdot 23 \\
6 \cdot 2163 \\
2 \cdot 7970\end{array}$ & $\begin{array}{r}437.92 \\
3.9619 \\
1.2294\end{array}$ \\
\hline 4 & $\begin{array}{l}0 \cdot 01 \\
0 \cdot 1 \\
0 \cdot 15\end{array}$ & $\begin{array}{r}737 \cdot 77 \\
6 \cdot 7671 \\
2 \cdot 9848\end{array}$ & $\begin{array}{r}737 \cdot 54 \\
6 \cdot 3449 \\
2 \cdot 7368\end{array}$ & $\begin{array}{r}727 \cdot 62 \\
7 \cdot 7476 \\
3 \cdot 2605\end{array}$ & $\begin{array}{r}722 \cdot 37 \\
6.5836 \\
2.9065\end{array}$ & $\begin{array}{r}721 \cdot 54 \\
4 \cdot 1080 \\
1 \cdot 2501\end{array}$ \\
\hline 5 & $\begin{array}{l}0 \cdot 01 \\
0 \cdot 1 \\
0 \cdot 15\end{array}$ & $\begin{array}{r}1047 \cdot 8 \\
6 \cdot 9442 \\
3 \cdot 0345\end{array}$ & $\begin{array}{r}1047 \cdot 2 \\
6 \cdot 5009 \\
2 \cdot 7786\end{array}$ & $\begin{array}{r}1039 \cdot 0 \\
7 \cdot 3674 \\
3 \cdot 2736\end{array}$ & $\begin{array}{r}1032 \cdot 1 \\
6 \cdot 7688 \\
2 \cdot 9601\end{array}$ & $\begin{array}{r}1030 \cdot 4 \\
4 \cdot 1794 \\
1 \cdot 2599\end{array}$ \\
\hline 10 & $\begin{array}{l}0 \cdot 01 \\
0 \cdot 1 \\
0 \cdot 15\end{array}$ & $\begin{array}{l}2409 \cdot 5 \\
7 \cdot 1963 \\
3 \cdot 1003\end{array}$ & $\begin{array}{r}2409 \cdot 6 \\
6.7252 \\
2.8345\end{array}$ & $\begin{array}{r}2422 \cdot 4 \\
7.5123 \\
3.2769\end{array}$ & $\begin{array}{r}2410 \cdot 0 \\
7 \cdot 0325 \\
3 \cdot 0347\end{array}$ & $\begin{array}{r}2400 \cdot 8 \\
4 \cdot 2784 \\
1 \cdot 2733\end{array}$ \\
\hline 20 & $\begin{array}{l}0 \cdot 01 \\
0 \cdot 1 \\
0 \cdot 15\end{array}$ & $\begin{array}{r}3615 \cdot 3 \\
7 \cdot 4057 \\
3 \cdot 1610\end{array}$ & $\begin{array}{r}3616 \cdot 1 \\
6.9301 \\
2 \cdot 8932\end{array}$ & $\begin{array}{r}3632 \cdot 2 \\
7.5328 \\
3.2669\end{array}$ & $\begin{array}{r}3617 \cdot 0 \\
7 \cdot 1016 \\
3 \cdot 0540\end{array}$ & $\begin{array}{r}3596.5 \\
4.3039 \\
1.2766\end{array}$ \\
\hline Plate & $\begin{array}{l}0 \cdot 01 \\
0 \cdot 1 \\
0 \cdot 15\end{array}$ & $\begin{array}{r}4324 \cdot 9 \\
7 \cdot 1768 \\
3.0824\end{array}$ & $\begin{array}{r}4322 \cdot 9 \\
6.6944 \\
2 \cdot 8148\end{array}$ & $\begin{array}{r}4356 \cdot 9 \\
7 \cdot 5169 \\
3.2525\end{array}$ & $\begin{array}{l}4342 \cdot 0 \\
7 \cdot 1250 \\
3 \cdot 0604\end{array}$ & $\begin{array}{r}4312 \cdot 5 \\
4 \cdot 3125 \\
1 \cdot 2777\end{array}$ \\
\hline
\end{tabular}

elasticity solution, while comparing with the results given by the first-order shear deformation theory.

Example 7. The exact solutions presented by Pagano $^{30}$ and Reddy ${ }^{31}$ are illustrated in this example to compare the response of higher-order theory in the sandwich plates and shells. A square plate with various $h / a$ ratios and a cylindrical shell with various $h / a$ and $R / a$ ratios are analysed here with following properties.

Face sheets:

$$
\begin{aligned}
E_{1} & =25 \times 10^{6} \mathrm{psi} ; \quad E_{2}=E_{3}=1 \times 10^{6} \mathrm{psi} ; \quad G_{12}=0.5 \times 10^{6} \mathrm{psi} \\
G_{23} & =0 \cdot 2 \times 10^{6} \mathrm{psi} ; \quad G_{13}=G_{12} ; \quad v_{12}=v_{23}=v_{13}=0 \cdot 25 ; \quad h_{\mathrm{f}}=0 \cdot 1 \mathrm{~h}
\end{aligned}
$$

Core:

$$
\begin{aligned}
E_{1} & =E_{2}=0.04 \times 10^{6} \mathrm{psi} ; \quad E_{3}=0.5 \times 10^{6} \mathrm{psi} ; \quad G_{12}=0.016 \times 10^{6} \mathrm{psi} \\
G_{13} & =G_{23}=0.06 \times 10^{6} \mathrm{psi} ; \quad v_{31}=v_{32}=v_{12}=0.25 ; \quad h_{c}=0.8 \mathrm{~h}
\end{aligned}
$$


hence,

$$
v_{12}=v_{23}=0 \cdot 02
$$

Table VIII(a) shows the values of non-dimensional centre deflection $\left(100 \times w E_{2} h^{3} / q a^{4}\right)$ in square orthotropic sandwich plate with different thickness ratios $(h / a)$. In the thin regime the results by all the theories are close to each other and are in good agreement with 3-D exact results presented by Pagano. ${ }^{30}$ The error in the results presented by first-order shear deformation theory (FOST) is upto 29 and 37 per cent in moderately thick and thick plates, respectively, when compared to 3D results. This error in the results presented by higher-order shear deformation theory (HOST) is only upto 5.8 per cent even in thick regime. Table VIII(b) shows the values of non-dimensional centre deflection $\left(100 \times w E_{2} h^{3} / q a^{4}\right)$ in orthotropic sandwich cylindrical shell with different $h / a$ ratios. The 3-D and finite element solutions of this problem are presented by Reddy ${ }^{31}$ and Menon, ${ }^{32}$ respectively. Again the error in the results presented by first-order shear deformation theory is very high ( 27 per cent) at $h / a=0 \cdot 1$ and even more (upto 38 per cent) at $h / a=0 \cdot 25$. The results presented by the present formulation of higher-order shear deformation theory are matching well with the finite element results of thin shell higher-order theory (Theory 1) and are close to the finite element results of thick shell higher-order theory (Theory 2) presented by Menon $^{32}$ and the 3-D elasticity solution presented by Reddy. ${ }^{31}$

Table VIII (a). Maximum normalized deflection in simply supported square orthotropic sandwich plate

\begin{tabular}{|c|c|c|c|c|c|c|}
\hline \multirow[b]{2}{*}{$h / a$} & \multicolumn{2}{|c|}{$\begin{array}{c}\text { HOST } \\
\text { (Integration scheme) }\end{array}$} & \multicolumn{2}{|c|}{$\begin{array}{c}\text { FOST } \\
\text { (Integration scheme) }\end{array}$} & \multirow[b]{2}{*}{ Pagano $^{30}$} & \multirow[b]{2}{*}{ Reddy $^{31}$} \\
\hline & Exact & Selective & Exact & Selective & & \\
\hline $0 \cdot 01$ & $0 \cdot 8888$ & 0.8910 & 0.8823 & 0.8854 & 0.892 & 0.8924 \\
\hline $0 \cdot 1$ & $2 \cdot 0846$ & $2 \cdot 0849$ & $1 \cdot 5604$ & $1 \cdot 5605$ & $2 \cdot 200$ & $2 \cdot 2005$ \\
\hline 0.25 & $7 \cdot 1538$ & $7 \cdot 1541$ & $4 \cdot 7667$ & $4 \cdot 7667$ & $7 \cdot 596$ & $7 \cdot 5965$ \\
\hline
\end{tabular}

Table VIII (b). Maximum normalized deflection in simply supported orthotropic sandwich cylindrical shell with $a / b=1, R_{1}=R, R_{2}=\infty$

\begin{tabular}{|c|c|c|c|c|c|c|}
\hline \multirow[b]{2}{*}{$h / a$} & \multirow[b]{2}{*}{$R / h$} & \multirow[b]{2}{*}{ HOST } & \multirow[b]{2}{*}{ FOST } & \multirow[b]{2}{*}{ Reddy $^{31}$} & \multicolumn{2}{|c|}{ Menon $^{32}$} \\
\hline & & & & & Theory 1 & Theory 2 \\
\hline \multirow[t]{5}{*}{$0 \cdot 1$} & 100 & $2 \cdot 1487$ & 1.6091 & $2 \cdot 2108$ & $2 \cdot 075$ & $2 \cdot 085$ \\
\hline & 50 & $2 \cdot 1537$ & $1 \cdot 6190$ & $2 \cdot 2218$ & $2 \cdot 076$ & $2 \cdot 096$ \\
\hline & 20 & $2 \cdot 1548$ & $1 \cdot 6314$ & $2 \cdot 2574$ & - & - \\
\hline & 10 & $2 \cdot 1402$ & $1 \cdot 6770$ & $2 \cdot 3115$ & $2 \cdot 096$ & $2 \cdot 203$ \\
\hline & 5 & 1.8971 & 1.6950 & $2 \cdot 1858$ & 1.944 & $2 \cdot 134$ \\
\hline \multirow[t]{5}{*}{$0 \cdot 25$} & 100 & $7 \cdot 5352$ & $4 \cdot 9881$ & $7 \cdot 6310$ & - & - \\
\hline & 50 & $7 \cdot 5280$ & $4 \cdot 9833$ & $7 \cdot 6669$ & - & - \\
\hline & 20 & $7 \cdot 5463$ & $5 \cdot 0045$ & $7 \cdot 7816$ & - & - \\
\hline & 10 & $7 \cdot 6088$ & $5 \cdot 0683$ & 7.9959 & - & - \\
\hline & 5 & $7 \cdot 7745$ & $5 \cdot 2991$ & $8 \cdot 5081$ & - & - \\
\hline
\end{tabular}




\section{CONCLUSIONS}

A $C^{0}$ Lagrangian isoparametric faceted quadrilateral element is presented for the analysis of general laminated plates and shells using a higher-order shear deformation theory. An obstacle course is passed to test the behaviour of the element and the elements' behaviour is seen to be satisfactory even in thin regime with refinement of mesh. The composite and sandwich laminated plate, cylindrical shell and spherical shell problems are analysed with the present formulation and results are compared with the exact and analytical solutions available in the literature and are found to be satisfactory. The element presented in this paper can be used in any type of shell structure in general and from thin to thick laminates. It is also seen that in case of sandwich laminates, the error in the displacement values of first-order shear deformation theory with respect to that of 3-D exact solution is large (up to 38 per cent), while the error in results of higher-order shear deformation theory is no more than 8 per cent even in thick laminates. Thus, the importance and usage of higher-order shear deformation theory is established especially for thick sandwich laminates.

\section{APPENDIX I}

The general transformation matrix $\mathbf{T}$ where in all the six components of stress and strain are considered, can be written as follows: ${ }^{33}$

$$
\mathbf{T}=\left[\begin{array}{cccccc}
l_{1}^{2} & m_{1}^{2} & n_{1}^{2} & l_{1} m_{1} & n_{1} l_{1} & m_{1} n_{1} \\
l_{2}^{2} & m_{2}^{2} & n_{2}^{2} & l_{2} m_{2} & n_{2} l_{2} & m_{2} n_{2} \\
l_{3}^{2} & m_{3}^{2} & n_{3}^{2} & l_{3} m_{3} & n_{3} l_{3} & m_{3} n_{3} \\
2 l_{1} l_{2} & 2 m_{1} m_{2} & 2 n_{1} n_{2} & \left(l_{1} m_{2}+l_{2} m_{1}\right) & \left(n_{1} l_{2}+n_{2} l_{1}\right) & \left(m_{1} n_{2}+m_{2} n_{1}\right) \\
2 l_{3} l_{1} & 2 m_{3} m_{1} & 2 n_{3} n_{1} & \left(l_{3} m_{1}+l_{1} m_{3}\right) & \left(n_{3} l_{1}+n_{1} l_{3}\right) & \left(m_{3} n_{1}+m_{1} n_{3}\right) \\
2 l_{2} l_{3} & 2 m_{2} m_{3} & 2 n_{2} n_{3} & \left(l_{2} m_{3}+l_{3} m_{2}\right) & \left(n_{2} l_{3}+n_{3} l_{2}\right) & \left(m_{2} n_{3}+m_{3} n_{2}\right)
\end{array}\right]
$$

where $l_{1}, m_{1}, n_{1}, \ldots$ etc. are the cosines of angles between the two sets of axes, i.e., lamina axes $(1,2,3)$ and the element axes $(x, y, z)$ and for the particular case of a fibre reinforced composite lamina, when the axis parallel to the fibres (direction-1) makes an angle $\theta$ with the $x$-axis and the axis perpendicular to the fibre and cross-fibre axes (direction-3) is coincident with $z$-axis, the co-ordinate transformation relation are expressed as

\begin{tabular}{l|lll} 
& \multicolumn{1}{|c}{$x$} & $y$ & $z$ \\
\hline 1 & $l_{1}=\cos \theta$ & $m_{1}=\sin \theta$ & $n_{1}=0$ \\
2 & $l_{2}=-\sin \theta$ & $m_{2}=\cos \theta$ & $n_{2}=0$ \\
3 & $l_{3}=0$ & $m_{3}=0$ & $n_{3}=0$
\end{tabular}

The transformation is accomplished as follows:

$$
\begin{gathered}
\boldsymbol{\varepsilon}^{\prime}=\mathbf{T} \boldsymbol{\varepsilon} \\
\boldsymbol{\sigma}=\mathbf{T}^{\mathrm{t}} \boldsymbol{\sigma}^{\prime} \quad \text { or } \quad \boldsymbol{\sigma}^{\prime}=\mathbf{T}^{-1^{\mathrm{t}}} \boldsymbol{\sigma}
\end{gathered}
$$


in which $\boldsymbol{\sigma}^{\prime}$ and $\boldsymbol{\varepsilon}^{\prime}$ are the vectors of stress and strain components, respectively, defined with reference to the lamina axes $(1,2,3)$ and the parameters $\boldsymbol{\sigma}$ and $\boldsymbol{\varepsilon}$ are the vectors of stress and strain components, respectively, with reference to laminate axes $(x, y, z)$.

Substituting the direction cosine values the final transformation matrix $\mathbf{T}$ is obtained as follows:

$$
\mathbf{T}=\left[\begin{array}{cccccc}
c^{2} & s^{2} & 0 & c s & 0 & 0 \\
s^{2} & c^{2} & 0 & -s c & 0 & 0 \\
0 & 0 & 1 & 0 & 0 & 0 \\
-2 c s & 2 s c & 0 & \left(c^{2}-s^{2}\right) & 0 & 0 \\
0 & 0 & 0 & 0 & c & s \\
0 & 0 & 0 & 0 & -s & c
\end{array}\right]
$$

in which $c=\cos \theta$ and $s=\sin \theta$. Finally, the transformation matrix $\mathbf{T}$ under the conditions $\sigma_{z} \simeq 0$ and $\varepsilon_{z}=0$ is obtained by eliminating 3 rd row and 3rd column of the matrix as follows:

$$
\mathbf{T}=\left[\begin{array}{ccccc}
c^{2} & s^{2} & c s & 0 & 0 \\
s^{2} & c^{2} & -s c & 0 & 0 \\
-2 c s & 2 s c & \left(c^{2}-s^{2}\right) & 0 & 0 \\
0 & 0 & 0 & c & s \\
0 & 0 & 0 & -s & c
\end{array}\right]
$$

\section{APPENDIX II}

Assuming

$$
H_{i}=\left(z_{L+1}^{i}-z_{L}^{i}\right) / i
$$

where $i$ takes an integer value from one to seven, the elements of the submatrices of the rigidity matrix can be readily obtained in the following forms:

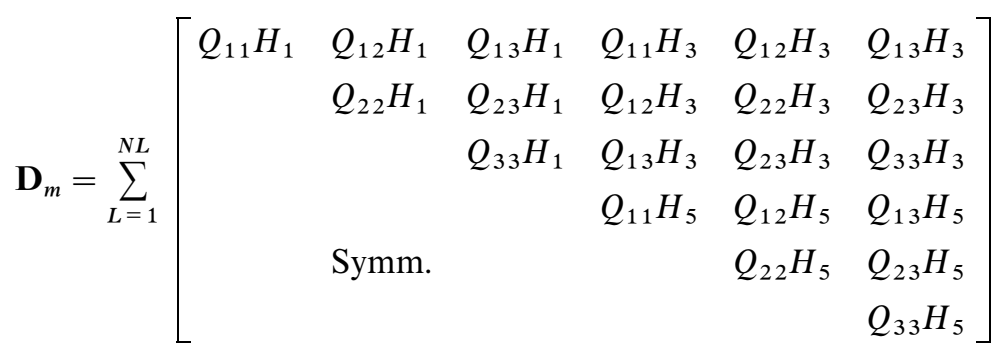




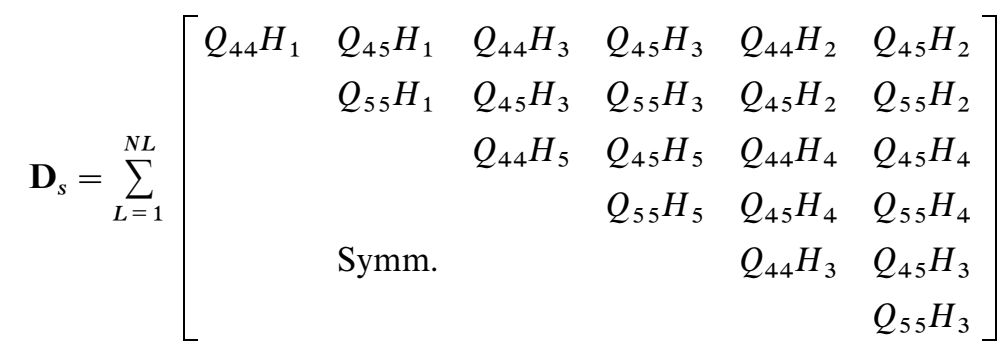

The elements of the $\mathbf{D}_{c}$ and $\mathbf{D}_{b}$ matrices are obtained by replacing $\left(H_{1}, H_{3}\right.$ and $\left.H_{5}\right)$ by $\left(H_{2}, H_{4}\right.$ and $\left.H_{6}\right)$ and $\left(H_{3}, H_{5}\right.$ and $\left.H_{7}\right)$, respectively, in the $\mathbf{D}_{m}$ matrix.

\section{APPENDIX III}

Matrix $\mathbf{L}_{\mathrm{g}}$ for the transformation of nodal displacement and forces may be defined using a matrix $\lambda$, a $3 \times 3$ matrix of direction cosines of the angles formed between the two sets of axes i.e.,

$$
\lambda=\left[\begin{array}{lll}
\lambda_{x X} & \lambda_{x Y} & \lambda_{x Z} \\
\lambda_{y X} & \lambda_{y Y} & \lambda_{y Z} \\
\lambda_{z X} & \lambda_{z Y} & \lambda_{z Z}
\end{array}\right]
$$

in which $\lambda_{x X}=$ cosine of angle between $x$ (local) and $X$ (global) axes, etc. The matrix $\mathbf{L}_{\mathrm{g}}$ is then given by

$$
\mathbf{L}_{\mathbf{g}}=\left[\begin{array}{cccccccccc}
\lambda_{x X} & \lambda_{x Y} & \lambda_{\mathrm{xZ}} & 0 & 0 & 0 & 0 & 0 & 0 & 0 \\
\lambda_{y X} & \lambda_{y Y} & \lambda_{y Z} & 0 & 0 & 0 & 0 & 0 & 0 & 0 \\
\lambda_{z X} & \lambda_{z Y} & \lambda_{z Z} & 0 & 0 & 0 & 0 & 0 & 0 & 0 \\
0 & 0 & 0 & \lambda_{x X} & \lambda_{x Y} & 0 & 0 & 0 & 0 & \lambda_{x Z} \\
0 & 0 & 0 & \lambda_{y X} & \lambda_{y Y} & 0 & 0 & 0 & 0 & \lambda_{y Z} \\
0 & 0 & 0 & 0 & 0 & \lambda_{x X} & \lambda_{x Y} & 0 & 0 & 0 \\
0 & 0 & 0 & 0 & 0 & \lambda_{y X} & \lambda_{y Y} & 0 & 0 & 0 \\
0 & 0 & 0 & 0 & 0 & 0 & 0 & \lambda_{x X} & \lambda_{x Y} & 0 \\
0 & 0 & 0 & 0 & 0 & 0 & 0 & \lambda_{y X} & \lambda_{y Y} & 0 \\
0 & 0 & 0 & \lambda_{z X} & \lambda_{z} & 0 & 0 & 0 & 0 & \lambda_{z Z}
\end{array}\right]
$$

Element stiffness sub-matrix for each node has the size of $10 \times 10$ with 10 th row and column as zero, but when the elements are coplanar, provision is made in the computer programme to modify the element stiffness matrix, introducing the drilling degree of freedom concept. $^{15}$ 


\section{ACKNOWLEDGEMENTS}

Second author is thankful to the Director, M. P. Council of Science and Technology, Bhopal, India and the Director, Shri G. S. Institute of Technology and Science, Indore, India for allowing him to conduct this research at IIT Bombay under FTYS scheme of MPCOST. Partial support of this research by the Aeronautics Research and Development Board, Ministry of Defence, Government of India through its Grant No. Aero/RD-134/100/10/94-95/801 is gratefully acknowledged.

\section{REFERENCES}

1. ABAQUS-General Purpose Finite-Element System, Hibbit, Karlsson and Sorensen, Inc., 100 Medway Street, Providence, RI 02906, Release 4.6, 1986.

2. ANSYS-General Purpose Finite-Element Program for Structural, Heat-Transfer, and Static-Electromagnetic Analysis, Swanson Analysis Systems, Inc., P.O. Box 65, Johnson Road, Houston, PA 15342, Revision 4.2A, 1987.

3. MSC/NASTRAN Application Manual, The MacNeal-Schwendler Corporation, Los Angeles, California, 1975.

4. NISA II-General Purpose, Finite-Element Programs for Linear and Non-linear, Static, Dynamic and Heat Transfer Analysis, Engineering Mechanics Research Corporation, P.O. Box 696, Troy, MI 48099, USA, Version 92.0, 1992.

5. K. J. Bathe, E. L. Wilson and F. E. Peterson, SAP IV-A Structural Analysis Program for Static and Dynamic Response of Linear Systems, College of Engineering, University of California, Berkeley, CA, 1973.

6. SAP80-Structural Analysis Programs, Computers and Structures Inc., 1918, University Avenue, Berkeley, CA, Version 85.03, 1984.

7. J. L. Meek and H. S. Tan, 'A faceted shell element with loof nodes', Int. J. Numer. Meth. Engng., 23, 49-67 (1986).

8. D. J. Allman, 'A basic flat facet finite element for the analysis of general shells', Int. J. Numer. Meth. Engng., 37, 19-35 (1994).

9. E. Madenci and A. Barut, 'A free-formulation-based flat shell element for non-linear analysis of thin composite structures', Int. J. Numer. Meth. Engng., 37, 3825-3842 (1994).

10. E. Onate, F. Zarate and F. Flores, 'A simple triangular element for thick and thin plate and shell analysis', Int. J. Numer. Methods Engng., 37, 2569-2582 (1994).

11. R. H. MacNeal, 'A simple quadrilateral shell element', Comput. Struct., 8, 175-183 (1978).

12. T. Belytschko, H. Stolarski, W. K. Liu, N. Carpenter and J. S. Ong-J, 'Stress projection for membrane and shear locking in shell finite elements', Comput. Methods Appl. Mech. Engng., 51, 221-258 (1985).

13. R. H. MacNeal and R. L. Harder, 'A proposed standard set of problems to test finite element accuracy', Finite Elements Anal. Des., 1, 3-20 (1985).

14. R. H. MacNeal, 'Eight nodes or nine?', Int. J. Numer. Meth. Engng., 33, 1049-1058 (1992).

15. R. D. Cook, 'Four-node 'flat' shell element: Drilling degrees of freedom, membrane-bending coupling, warped geometry, and behaviour', Comput. Struct., 50, 549-555 (1994).

16. H. Kraus, Thin Elastic Shells, Wiley, New York, 1967.

17. E. Reissner, 'The effect of transverse shear deformation on the bending of elastic plates', ASME, J. Appl. Mech., 12, 69-76 (1945).

18. R. D. Mindlin, 'Influence of rotatory inertia and shear in flexural motions of isotropic elastic plate', ASME, J. Appl. Mech., 18, 31-38 (1951).

19. O. C. Zienkiewicz and R. L. Taylor, The Finite Element Method, 3rd edn, Tata McGraw-Hill, New Delhi, 1979.

20. B. N. Pandya, 'Finite element analysis of laminated composite plates using a higher-order displacement model', Compos. Sci. Technol., 32, 137-155 (1988).

21. A. C. Scordelis and K. S. Lo, 'Computer analysis of cylindrical shells', J. Am. Concr. Inst., 61, 539-561 (1964).

22. A. C. Scordelis, 'Analysis of cylindrical shells and folded plates', Concrete Thin shells, Am. Concr. Inst. Report SP $28-N, 1971$

23. L. S. D. Morley and A. J. Morris, 'Conflict Between Finite Elements and Shell Theory', Royal Aircraft Establishment Report, London, 1978.

24. T. Kant and M. P. Menon, 'Estimation of interlaminar stresses in fibre reinforced composite cylindrical shells', Comp. Struct., 38, 131-147 (1991).

25. B. N. Pandya, 'Higher-Order theories and finite element evaluations for multilayer composite plates', Ph.D. Thesis, Department of Civil Engineering, Indian Institute of Technology Bombay, India, 1987.

26. J. G. Ren, 'Exact solutions for laminated cylindrical shells in cylindrical bending', Compos. Sci. Techno., 29, 169-187 (1987).

27. K. J. Bathe and E. L. Wilson, Numerical Methods in Finite Element Analysis, Prentice-Hall of India Pvt Ltd, New Delhi, 1987. 
28. J. G. Ren, 'Analysis of simply supported laminated circular cylindrical shells', Compos. Struct., 11, 277-292 (1989).

29. A. Bhimaraddi, 'Three-dimensional elasticity solution for static response of orthotropic doubly curved shallow shells on rectangular planform', Compos. Struct., 24, 67-77 (1993).

30. N. J. Pagano, 'Exact solutions for rectangular composite and sandwich plates', J. Compos. Mater., 4, 20-34 (1970).

31. T. S. Reddy, 'Three dimensional elastostatic analysis of fibre reinforced composite laminated shells', M.Tech. Dissertation, Department of Civil Engineering, Indian Institute of Technology Bombay, India, 1992.

32. M. P. Menon, 'Refined theories and finite element evaluations for multilayered composite shells', Ph.D. Thesis, Department of Civil Engineering, Indian Institute of Technology Bombay, India, 1991.

33. R. D. Cook, Concepts and Applications of Finite Element Analysis, 3rd edn, Wiley, New York, 1989. 